INRA Prod. Anim.,

2014, 27 (3), 223-234

\title{
Le phénotypage de la qualité des produits animaux : enjeux et innovations
}

\author{
E. LE BIHAN-DUVAL ${ }^{1}$, R. TALON ${ }^{2}$, M. BROCHARD ${ }^{3,4,5}, J$. GAUTRON ${ }^{1}$, \\ F. LEFĖVRE ${ }^{6}$, C. LARZUL ${ }^{4,5}$, E. BAÉZZA ${ }^{1}$, J.-F. HOCQUETTE ${ }^{7,8}$ \\ ${ }^{1}$ INRA, UR83 Recherches Avicoles, F-37380, Nouzilly, France \\ 2 INRA, UR0454 Microbiologie, F-63122 Saint-Genès-Champanelle, France \\ ${ }^{3}$ Institut de l'Elevage, 149 rue de Bercy, F-75595 Paris, France \\ ${ }^{4}$ INRA, UMR1313 GABI, F-785352 Jouy-en-Josas, France \\ 5 AgroParisTech, UMR1313 GABI, F-75231 Paris, France \\ 6 INRA, UR1037 LPGP, F-35042 Rennes cedex, France \\ 7 INRA, UMR1213 Herbivores, F-63122 Saint-Genès-Champanelle, France \\ 8 Clermont Université, VetAgro Sup, UMR1213 Herbivores, BP 10448, F-63000 Clermont-Ferrand, France
}

Courriel : elisabeth.duval@tours.inra.fr

Maîtriser la qualité des produits suppose de pouvoir l'objectiver à partir de mesures fiables, faciles d'utilisation et si possible précoces et non invasives. Appliqué à un panel de plus en plus large de critères de qualité, le phénotypage à haut débit est nécessaire au développement de la sélection génétique ou génomique, de la biologie prédictive et de l'élevage de précision.

La qualité est une notion qui traduit l'aptitude du produit à répondre aux attentes du consommateur-citoyen et plus largement aux demandes d'un marché en constante évolution. Alors que la part des dépenses d'alimentation dans la consommation des ménages est passée de plus de $21 \%$ en 1959 à environ $13 \%$ en 2010 (Hanne et Roux 2012), les modes de consommation se sont largement diversifiés. A côté des produits standards se sont développées des productions sous signe de qualité (produits biologiques, AOC, Label Rouge ou certifiés) en même temps qu'une plus forte consommation de produits élaborés pour des raisons de praticité. Face à cette diversité des demandes et des systèmes de production, il existe un besoin d'objectivation de la qualité afin d'accompagner les démarches d'amélioration et d'éclairer les choix des consommateurs. Le phénotypage des produits animaux consiste à développer de telles mesures pour apprécier la qualité de ces produits. Ces mesures doivent être fiables, faciles d'utilisation et si possible précoces et non invasives (Le Bihan-Duval et al 2013a).

La qualité d'un produit résulte de ses différentes propriétés intrinsèques et de leur perception par le consommateur. Dans certains pays (France, Europe du sud principalement), la qualité fait largement référence aux qualités sensorielles, aux aptitudes culinaires et au goût des produits. Dans d'autres pays (Europe du nord principalement), la relation à l'alimentation apparaît plus « fonction- nelle ». Avec la qualité sanitaire qui reste un enjeu majeur de santé publique, les consommateurs des pays développés accordent aussi une importance croissante à la qualité nutritionnelle en lien avec la valeur « santé » des aliments (Dockès et al 2011). Enfin, l'augmentation de la consommation de produits élaborés implique de s'intéresser à la qualité technologique du produit qui conditionne son aptitude à la transformation. Le phénotypage doit donc intégrer ces différentes composantes de la qualité, pour les évaluer, révéler de possibles antagonismes, et choisir la démarche d'amélioration la plus adaptée en fonction du marché visé.

La qualité a ceci de complexe qu'elle s'apprécie sur le produit final, mais qu'elle s'élabore très en amont, en interaction étroite avec un système d'élevage. Si le niveau d'élaboration des produits augmente, les études d'opinion montrent une recherche par les consommateurs de plus de " naturalité » à laquelle l'industrie agroalimentaire répond en cherchant à limiter voire supprimer les additifs alimentaires (conservateurs, arômes, texturants...). Ces évolutions montrent toute l'importance de mieux contrôler l'homogénéité de la qualité du produit initial, en sélectionnant des animaux aux aptitudes favorables et en optimisant les pratiques d'élevage. Aussi le phénotypage ne peut-il se limiter à développer des outils de contrôle de la qualité du produit final mais doit-il considérer la recherche de mesures prédictives et de biomar- queurs accessibles le plus précocement possible sur le produit initial voire l'animal (figure 1).

Les possibilités de sélection génétique ou génomique sur la qualité des produits dépendent largement de l'accès à des mesures pertinentes (c'est-à-dire corrélées aux qualités finales du produit), mais aussi rapides et donc automatisables et si possible non destructives ou invasives. Ce phénotypage « horizontal » applicable à large échelle doit, autant que possible, être valorisable en élevage pour piloter au mieux les animaux, puis optimiser les procédés de transformation ou le mode de commercialisation en fonction de la qualité prédite. La compréhension des bases biologiques de la qualité à des fins de recherche requiert, quant à elle, une caractérisation fine des mécanismes impliqués grâce à la mesure de phénotypes élémentaires (transcrits, protéines, paramètres sanguins, hormones, métabolites...) (Lagarrigue et Tixier-Boichard 2011) qui participent à l'élaboration du phénotype d'intérêt. De ce phénotypage « vertical», sur un nombre plus restreint d'animaux, pourra découler de nouveaux biomarqueurs utilisables ensuite comme critère de sélection ou pour l'élevage de précision.

L'évaluation en routine ou la construction de modèles de prédiction de la qualité du produit passe donc par le développement d'un phénotypage à haut débit (figure 1), dont nous examinerons successivement les verrous techniques puis 
Figure 1. Stratégie de phénotypage de la qualité des produits.

Verrous scientifiques

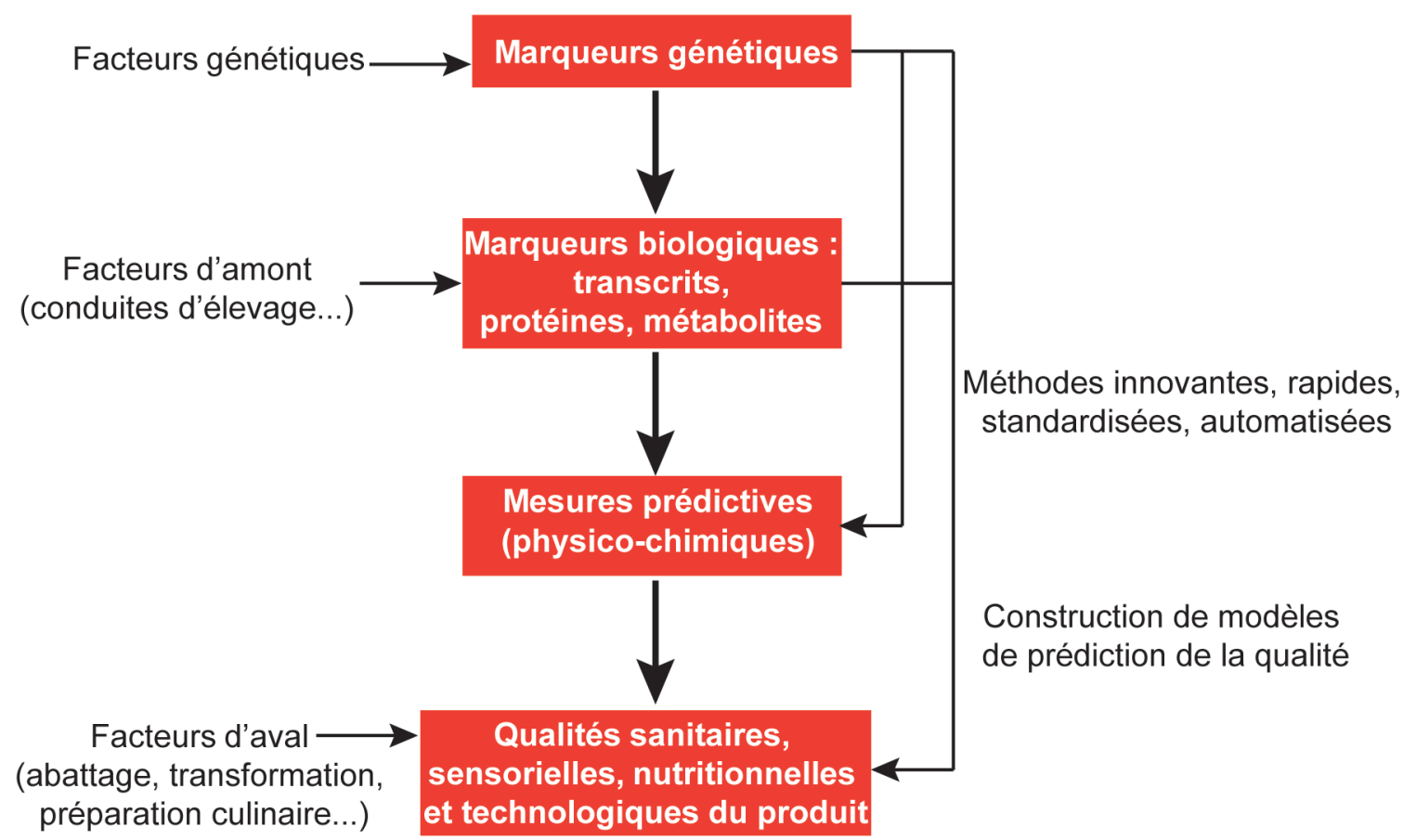

Le phénotypage à haut débit de la qualité intègre la recherche de marqueurs génétiques ou biologiques précoces, le développement de mesures prédictives pertinentes (de type physico-chimiques notamment) et l'évaluation en routine des qualités sanitaires, sensorielles, nutritionnelles, ou technologiques du produit. Les verrous scientifiques sont de mieux comprendre l'influence des facteurs d'amont et d'aval sur les mesures prédictives ou les critères de qualité eux-mêmes afin de répondre aux attentes des consommateurs-citoyens, grâce à la sélection, l'élevage de précision et la maîtrise des procédés d'abattage et de transformation. Les verrous technologiques sont i) de développer des méthodes innovantes, rapides, standardisées, automatisées des mesures prédictives ou des critères de qualité, et ii) de développer des modèles de prédiction de la qualité à partir de mesures accessibles en routine.

les apports pratiques en réponse aux problématiques de qualité pour les produits carnés, le lait et les œufs.

\section{1 / Les verrous technologi- ques du phénotypage de la qualité des produits animaux}

Pour de nombreux produits, le produit consommé est de plus en plus élaboré ce qui implique de nombreuses étapes de cuisson, transformation, conservation, si l'on veut aller jusqu'à l'évaluation de la qualité du produit final. Ceci montre la nécessité de rechercher des mesures prédictives de la qualité, fiables et rapides, ou des marqueurs (génétiques ou biologiques) accessibles sur l'animal ou ses tissus (figure 1). Par exemple, si l'on se réfère au cas de la viande, le rendement technologique (phénotype d'intérêt) peut dans certaines espèces être prédit à partir de la mesure du pH ultime (mesure prédictive) lui-même influencé par la teneur en glycogène (biomarqueur). Ces différents niveaux du " phénotypage » et les verrous technologiques associés sont abordés pour différentes composantes de la qualité.

\section{1 / Développer des méthodes rapides et standardisées de détection et de quantification des contaminants biologiques ou chimiques en lien avec la sécurité des aliments}

Les garanties d'hygiène et de sécurité étant le premier critère de choix des consommateurs, il importe de réduire les risques de contaminations chimiques ou biologiques. C'est le cas en particulier des principales bactéries pathogènes identifiées dans les aliments d'origine animale : Listeria monocytogenes, Staphylococcus aureus, Salmonella spp., Escherichia coli producteurs de shigatoxines (STEC), Campylobacter, Clostridium botulinum, Clostridium perfringens, Yersinia enterolitica, Bacillus cereus, dont la prévalence va dépendre des produits (EFSA 2011, Feurer et al 2013, Jamet et al 2013). Parmi ces pathogènes, certains sont soumis à des normes réglementaires européennes (directives du « paquet hygiène » 2073/2005 modifié). Suivant la bactérie pathogène et l'aliment concerné, la norme exige l'absence dans le produit ou tolère un faible niveau de population. A titre d'exemple, pour
Salmonella, le critère est « absence dans $25 \mathrm{~g}$ » pour les produits mis sur le marché pendant leur durée de conservation. Cela implique en priorité de développer des méthodes rapides de détection et ou de quantification des pathogènes pour pouvoir à la fois garantir la qualité des produits et refuser les lots non conformes avant leur entrée dans la chaîne alimentaire. De nombreux outils moléculaires ont été développés pour les pathogènes dont la majorité est basée sur la PCR et la PCR quantitative. Dans tous les cas, il faut extraire l'ADN d'un aliment avant de réaliser l'étape de la PCR et de nombreuses études ont été consacrées à ce volet ces dernières années. La recherche de ces bactéries pathogènes doit passer par des méthodes ciblées (PCR spécifique d'espèces, de sérotypes voire de facteurs de virulence) car elles contaminent l'aliment dans la majorité des cas à des taux très faibles et font souvent partie des populations sous dominantes qu'il n'est pas possible de mettre en évidence par des approches globales de métagénomique qui révèlent les populations dominantes. Les méthodes de mesure des contaminants biologiques (ou chimiques) sont en constante évolution du fait à la fois 
des progrès techniques mais aussi de l'émergence de nouveaux risques. Leur standardisation et leur mode d'application sont des étapes importantes à considérer en raison de l'impact sur la fiabilité et le temps de mesure, mais aussi des conséquences économiques importantes liées à la mise en évidence d'un pathogène (Jez et al 2010). Si le contrôle de la qualité sanitaire de l'aliment est un élément crucial pour la sécurité de la chaîne alimentaire, la maîtrise en amont des contaminations fait partie intégrante de la stratégie de prévention. Les travaux sur le portage animal (dans le cas de bactéries comme Salmonella et Campylobacter) restent donc un volet de recherche important qui nécessite lui aussi une standardisation des tests (choix de la souche étudiée, cinétique de contamination...) (Velge et al 2008).

Les produits animaux peuvent faire l'objet de contaminations chimiques provenant de différentes sources : $i$ ) résidus de pesticides utilisés lors des cultures des matières premières utilisées dans l'alimentation animale; ii) résidus de produits de traitements vétérinaires (antibiotiques, anticoccidiens) lorsque les délais de retrait ne sont pas respectés, contaminants de l'environnement (PolyChloroBiphényles - PCBs -, dioxines, métaux lourds) et iii) toxines produites par les moisissures (mycotoxines) pouvant se développer sur les matières premières utilisées dans l'alimentation animale en particulier lorsque celles-ci ne peuvent être traitées par des antifongiques (cas des cultures biologiques par exemple). Un des objectifs du projet ANR ALID Someat (2013-2015) est d'exposer à différents contaminants et dans des conditions parfaitement contrôlées des poulets, afin de déterminer des biomarqueurs (gènes, protéines et/ou métabolites) de ces contaminants au niveau hépatique. Ceux-ci pourraient ensuite être utilisés par les laboratoires de contrôle lors de contaminations accidentelles d'animaux de rente et donc de produits carnés. En effet, Berge et al (2011) ont montré que l'analyse de la composition en composés volatils du foie de poulets permettait de différencier les animaux contaminés avec des PBDEs ( "polybrominated diphenyl ethers ») ou des coccidiostatiques des animaux non contaminés.

\section{2 / Améliorer les méthodes de référence pour l'appréciation de la qualité sensorielle et rechercher des mesures prédictives applica- bles à large échelle}

Concernant les caractéristiques sensorielles, la méthode de choix reste la dégustation par un jury entraîné sur la base de tests discriminatifs pour repérer des différences entre deux ou plusieurs produits ou descriptifs pour évaluer un « profil sensoriel » à partir d'une liste des descripteurs prédéfinis. Ces tests sont aujourd'hui très largement utilisés en agroalimentaire pour mettre en relation les caractéristiques du produit et son appréciation par le consommateur. Les tests réalisés avec des personnes non entraînées permettent, quant à eux, de se rapprocher le plus possible du comportement réel du consommateur (Watson et al 2008a). Cependant, quel que soit leur type, les tests sensoriels sont difficilement applicables sur un grand nombre d'échantillons en raison de leur coût élevé et de la nécessité de plusieurs jurys. De plus, ils présentent des limites technologiques et statistiques liées à la variabilité de la mesure entre jurys et entre dégustateurs au sein d'un même jury (Hocquette et al 2007). Une amélioration des techniques de référence d'appréciation des caractéristiques sensorielles avec des consommateurs (protocoles standards, maîtrise de la variabilité des réponses...) est donc à rechercher. Comme nous le verrons dans le cas de la viande bovine, ces recherches doivent être accompagnées du développement de mesures et de modèles prédictifs de la qualité sensorielle. La perception sensorielle et l'acceptabilité d'un produit résultant d'interactions complexes entre plusieurs composantes (goût, texture, odeur, couleur...), il existe aussi un besoin d'approches intégrées afin de mieux les évaluer en termes d'impact sur le comportement des consommateurs.

\section{3 / Développer des mesures à haut débit de la composition fine et des propriétés technologiques des produits}

Les qualités nutritionnelle, technologique et sensorielle dépendent largement des caractéristiques physico-chimiques du produit, mesurées grâce à de nombreuses techniques analytiques de laboratoire. Ainsi, les méthodes chimiques permettent d'évaluer la composition globale du produit en eau, lipides, protéines et cendres, ainsi que la composition fine en acides gras, acides aminés, sucres, pigments, minéraux et cholestérol, la quantité et la solubilité du collagène (dans le cas de la viande) ou encore le niveau d'oxydation des lipides ou des protéines. D'autres méthodes, physiques ou mécaniques, ont été développées pour mesurer l'acidité du produit $(\mathrm{pH})$, l'état de l'eau (paramètre $\mathrm{a}_{\mathrm{W}}$ ), la couleur, la texture (mesure de résistance au cisaillement ou à la compression), le pouvoir de rétention en eau (tests de gravimétrie, de compression, de centrifugation ou de cuisson), les rendements de transformation, le temps de coagulation et les propriétés rhéologiques des caillés pour le lait, etc. Ces mesures ont largement été améliorées et standardisées pour accroître leur précision et servent pour partie aujourd'hui de références ou, à défaut, de méthodes de calage (voir par exemple Hocquette et al (2007) et Petracci et Baéza (2011) pour la qualité de la viande, les normes ISO 15884 et 15885 pour la mesure des acides gras du lait en chromatographie en phase gazeuse, ainsi que O'Callaghan et al (2002) et De Marchi et al (2007) pour les propriétés de coagulation du lait). En revanche, pour la plupart, ces méthodes sont difficilement applicables à large échelle, en particulier dans des conditions industrielles où manipulations et temps de mesure doivent être réduits. Il existe donc un besoin de méthodes alternatives à haut débit de mesure de la composition et des propriétés technologiques des produits. L'intérêt de nouvelles technologies optiques, physiques ou par imagerie sera illustré dans la suite de l'article au travers d'exemples empruntés aux différentes filières animales.

\section{4 / Rechercher des marqueurs biologiques et génétiques précoces de la qualité du produit}

Outre les caractéristiques physicochimiques et structurales du produit, les études s'orientent vers la recherche de biomarqueurs tels les transcrits, les protéines ou les métabolites dont la quantité serait un bon prédicteur de la mesure d'un caractère d'intérêt difficilement mesurable (Lagarrigue et Tixier-Boichard 2011). Les programmes de génomique fonctionnelle ont permis d'établir des listes de biomarqueurs associés à la variabilité de différents critères de qualité. Les études menées sur la qualité de la viande montrent que, quelle que soit l'espèce, les mécanismes biologiques sont complexes et qu'un grand nombre de biomarqueurs doit être analysé ensemble pour envisager le développement d'outils de prédiction. La stratégie est donc d'élaborer des outils (de type puce à ADN ou puce à anticorps) permettant de quantifier à moindre coût et simultanément ces marqueurs au niveau des transcrits ou des protéines sur un grand nombre d'échantillons à la fois (Picard et al 2012).

L'identification de biomarqueurs très précoces de la qualité des produits, accessibles sur l'animal vivant et dont on pourrait suivre l'évolution en lien avec l'environnement d'élevage, constituerait un outil de pilotage précieux pour les filières de production animale. Ainsi, des premières études commencent à explorer l'intérêt pour la prédiction des phénotypes des profils métabolomiques, en tant que signature métabolique d'un individu. Une technique comme la Résonance Magnétique Nucléaire $(\mathrm{RMN})$ peut être utilisée 
à grande échelle sur des fluides (de type plasma ou urine) et donne en sortie un spectre par individu dont chaque pic correspond à un ou plusieurs métabolites (Bothwell et Griffin 2011). Appliquée à partir d'un prélèvement de sang chez le porc en croissance (à environ $60 \mathrm{~kg}$ ), cette technique a donné des résultats encourageants pour la prédiction de la teneur en viande de la carcasse (Rohart et al 2012). En revanche, la prédiction n'était pas satisfaisante pour les phénotypes liés à la qualité de la viande, pour lesquels l'information métabolomique au moment de l'abattage pourrait être plus pertinente. L'identification des marqueurs génétiques associés à des critères de qualité est également une approche très prometteuse car permettant un diagnostic à la fois précoce et non invasif sur l'animal. Notons que, parmi les rares polymorphismes aujourd'hui disponibles pour la sélection animale, plusieurs concernent des paramètres de qualité des produits. C'est le cas des gènes Hal (Fujii et al 1991) et $R N$ (Milan et al 2000) à l'origine de défauts majeurs de qualité de viande chez le porc, de la myostatine qui affecte le poids et la conformation des carcasses mais aussi la qualité de la viande bovine (Allais et al 2010), du gène FMO3 responsable de l'apparition d'odeur de poisson dans les œufs (Honkatukia et al 2005), du gène $B C M O 1$ contrôlant la variation de coloration jaune ainsi que la teneur en lutéine et en zéaxanthine dans la viande de poulet (Le Bihan-Duval et al 2011) ou encore du gène DGAT1 jouant sur la composition et les propriétés de coagulation du lait (Grisart et al 2002). Avec le développement d'outils de génotypage à haute ou très haute densité (plusieurs dizaines ou centaines de milliers de marqueurs SNP), certaines limites liées à la faible précision de la localisation des régions génomiques (QTL) et à l'identification des gènes candidats contrôlant les phénotypes d'intérêt s'estompent. La qualité du phénotypage (pertinence et fiabilité des mesures utilisées) apparaît donc comme le verrou majeur à lever pour les futures études de génétique.

\section{2 / Les questions posées en termes de qualité selon les filières et exemples d'inno- vations dans le domaine du phénotypage}

\section{1 / Les produits carnés}

Les problématiques en termes d'amélioration de la qualité de la viande sont très variables entre espèces, ne serait-ce que parce qu'elles sont abattues à des stades physiologiques différents et destinées à des modes de commercialisation variés (Renand et al 2003). Dans ce chapitre, nous nous intéresserons successivement au cas du porc et du poulet, pour lesquels la viande issue d'animaux encore en croissance est valorisée principalement sous forme découpée ou transformée, des bovins, dont la viande issue d'animaux matures est principalement valorisée en frais, et des poissons, qui présentent des spécificités biologiques ou liées au mode d'élevage.

\section{a) Le porc et le poulet}

Chez le porc, environ les deux tiers de la carcasse sont destinés à l'industrie de la transformation ce qui impose de mâ̂triser la qualité technologique de la viande. L'existence d'une base génétique de cette qualité a été démontrée, via notamment l'identification des gènes $R N$ et $H A L$ à l'origine des défauts majeurs que sont les viandes « acides » ou «PSE ». Pour ces gènes des tests moléculaires ont été développés afin d'éradiquer ou au moins de contrôler l'incidence des allèles défavorables dans les populations sélectionnées. L'aptitude technologique du jambon a également été prise en compte par des approches conventionnelles de sélection, s'appuyant sur la mesure du $\mathrm{pH}$ ultime ( $\mathrm{pHu}$ ) ou d'un index synthétique de qualité de la viande combinant $\mathrm{pHu}$, clarté et capacité de rétention en eau de la viande. Pour les volailles, les habitudes alimentaires évoluant vers une moindre consommation de carcasses entières au profit des morceaux découpés et des produits élaborés, la qualité de la viande revêt aussi une importance croissante. La variation non maîtrisée du pHu est à l'origine de l'apparition de défauts comme les viandes acides, présentes chez près de $20 \%$ des poulets standard à croissance rapide et $50 \%$ des poulets label à croissance lente (Berri et al 2010). Contrairement au porc, on ne connaît pas de polymorphismes génétiques associés à ces défauts, même si l'on sait que la génétique joue un rôle déterminant dans le contrôle du $\mathrm{pH}$ chez le poulet (Le Bihan-Duval et al 2008, Chabault et al 2012). Chez ces deux espèces, la prédiction du rendement technologique par des procédés rapides et simples à mettre en œuvre reste un enjeu pour les applications en sélection ou le contrôle de la qualité en abattoir. Les travaux menés chez le porc (sur le jambon ou la longe) ont montré que des technologies comme la spectrométrie dans le visible ou le proche infrarouge constituent des alternatives intéressantes à la mesure du $\mathrm{pH}$ ultime en termes de qualité de la prédiction et de fiabilité des mesures en conditions industrielles (Vautier et al 2011). L'intérêt d'une telle technologie chez le poulet est aujourd'hui à l'essai (programme CASDAR Optiviande 2014-2016). Chez le poulet, le contrôle individuel de la viande en abattoir étant difficilement réalisable du fait de cadences trop élevées (jusqu'à 12000 poulets à l'heure), les recherches s'orientent aussi vers la prédiction de la qualité sur l'animal vivant à l'aide de biomarqueurs. Ainsi, une étude exploratoire est-elle en cours pour comparer, à partir d'échantillons sanguins prélevés à l'abattoir, le profil métabolomique de deux lignées de poulets sélectionnées de façon divergente sur leur $\mathrm{pH}$ ultime (Le BihanDuval et al 2013b). De ce type d'approche exploratoire pourraient découler de nouveaux outils de phénotypage utiles à la sélection ou à la prédiction de la qualité en élevage, chez le poulet et à terme chez d'autres espèces d'intérêt.

Chez le porc comme le poulet, la teneur et le profil en acides gras de la viande sont d'autres critères importants du fait de leur impact sur les qualités nutritionnelle et sensorielle. Chez le porc, la sélection pour une augmentation du pourcentage de muscle par rapport au gras et l'utilisation majoritaire du Piétrain en tant que verrat parental se sont accompagnées d'une diminution des teneurs en Lipides IntraMusculaires (LIM) pour atteindre des valeurs jugées limites en termes de tendreté et de jutosité. Chez le poulet, contrairement au porc, la réduction de l'engraissement "périphérique » ne semble pas avoir affecté la teneur en gras intramusculaire qui, quel que soit le type de souche, reste en général faible (de l'ordre de 1\%). Néanmoins, la sélection de poulets à plus faible teneur en lipides correspond à une demande des charcutiers pour la fabrication de blanc de poulet à faible teneur en matière grasse (moins de 2,5\%). Le dosage des LIM par méthode chimique restant onéreux et inenvisageable à grande échelle, des technologies alternatives doivent être recherchées. Chez le poulet ou le canard, la spectroscopie en proche infrarouge (SPIR) peut être utilisée pour estimer la teneur en lipides du muscle, mais la précision est meilleure lorsque la mesure est réalisée sur un broyat de muscle au laboratoire que sur muscle entier à l'abattoir (Bastianelli et al 2009, Chartrin et al 2010, figure 2). Afin d'aller vers du plus haut débit, de récents travaux ont testé l'intérêt de l'imagerie chez le porc. Les premiers résultats sont intéressants puisqu'en limitant la préparation des échantillons à un simple conditionnement à une température de $5^{\circ} \mathrm{C}$, la $\mathrm{RMN}$ permet de prédire la teneur en lipides d'environ 500 échantillons par jour (Davenel et al 2012). Non seulement la teneur mais aussi le profil en acides gras est un élément important à contrôler, en particulier pour les filières productrices de viandes riches en oméga-3 telle que la filière Bleu-Blanc-Cœur. En travaillant sur une base de données contenant $50 \%$ de porcs provenant de cette filière et $50 \%$ de la filière conventionnelle, une étude récente a montré l'intérêt des mesu- 
Figure 2. Utilisation de la spectroscopie dans le proche infrarouge pour le dosage de la teneur en lipides du filet de poulet.

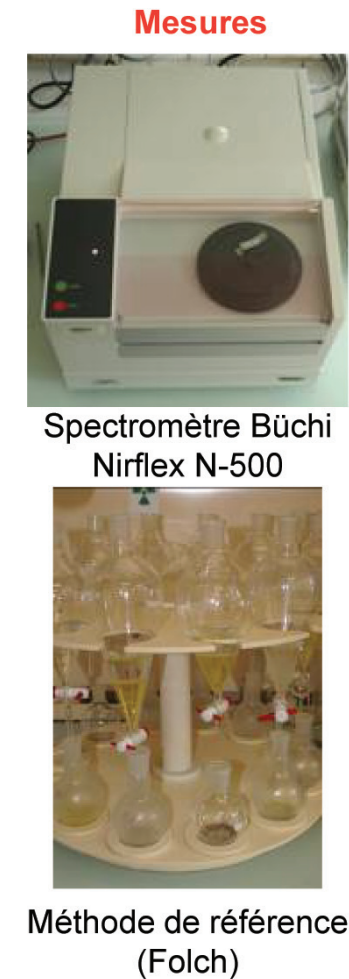

(Folch)
Modèles statistiques

Base de données réalisée avec 877 filets de poulets de souche lourde et 457 filets de poulets Label Rouge
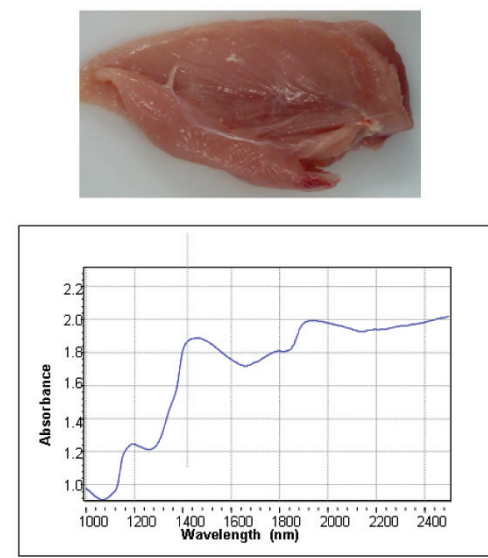

Spectre obtenu avec un filet de poulet broyé

\section{Equations de prédiction}

Pour la calibration, l'erreur

standard est de 0,21\%

et pour la validation elle est de $0,24 \%$

avec un $\mathrm{R}^{2}=0,83$ et un RPD

(critère de qualité du modèle) $=1,95$

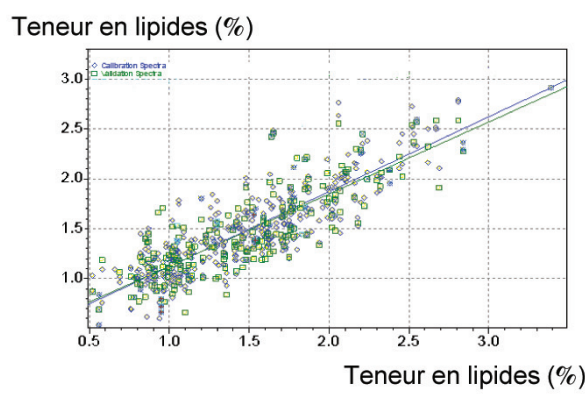

Relation entre les valeurs prédites et mesurées de la teneur en lipides de filets de poulets

Le dosage des lipides intramusculaires par méthode chimique restant onéreux et inenvisageable à grande échelle, des technologies alternatives doivent être recherchées. La spectroscopie dans le proche infrarouge peut être utilisée pour estimer la teneur en lipides après simple broyage des muscles (Chartrin et al 2010).

res par SPIR sur la chaîne d'abattage pour la prédiction de la teneur en oméga-3 dans les tissus adipeux de porc (Mairesse et al 2012). Comme l'illustre cet exemple, la fiabilité et donc l'intérêt des mesures par SPIR passe par la constitution de bases de données présentant suffisamment de variabilité (en lien avec l'alimentation, la génétique, le mode d'élevage...) pour établir un modèle de prédiction du constituant à doser.

Les deux types de filières doivent par ailleurs faire face à l'existence de défauts de structure qui affectent l'ensemble des qualités (technologiques, nutritionnelle ou sensorielle) de la viande. C'est le cas du défaut de viande déstructurée qui toucherait de l'ordre de $20 \%$ des jambons de porc et dont les conséquences sont majeures sur les pertes au tranchage et la qualité sensorielle (saveur métallique, texture pâteuse) du jambon cuit (Vautier, communication personnelle). Chez le poulet, on assiste aussi à une recrudescence de défauts musculaires tels que les « stries blanches » qui dégradent l'acceptabilité du produit par le consommateur ainsi que les qualités nutritionnelles et technologiques de la viande (Owens et Kuttappan 2013). Outre le besoin d'outils de suivi de l'incidence de ces défauts pour les abattoirs, les recherches s'orientent vers une meilleure caractérisation des propriétés histologiques et biochimiques des muscles affectés à l'aide de différentes techniques analytiques (protéomique, métabolomique, microscopie biphotonique...). Un partage des techniques et des connaissances entre les deux espèces devrait permettre de mieux comprendre l'étiologie des défauts musculaires et d'identifier des pistes d'amélioration en lien avec la génétique et le système d'élevage.

\section{b) Les bovins à viande}

Même si les qualités nutritionnelles et de « praticité » du produit doivent être considérées comme pour les autres filières, les qualités organoleptiques sont des critères majeurs pour l'espèce bovine. Comme le montrent toutes les enquêtes auprès des consommateurs (Dransfield et Zamora 1997, Grunert et al 2004), la tendreté est le critère sensoriel le plus important. C'est aussi un critère au déterminisme complexe et d'origine multifactorielle. C'est le critère de qualité le plus variable, et donc le plus difficile à maîtriser ou à prédire (Morgan et al 1991, Culioli 1998, Geay et al 2001). Une enquête récente a montré que les consommateurs étaient relativement satisfaits de la tendreté de la viande bovine qui leur était proposée en France au moins pour certaines pièces, mais avec des degrés de satisfaction différents selon le type de morceau consommé et sans relation nette entre le prix de vente et la tendreté du produit (Normand et al
2009). Comme l'a montré une autre enquête au niveau européen (Verbeke et al 2010), les consommateurs souhaitent être mieux informés du niveau de qualité, et en particulier de la tendreté qu'ils peuvent espérer au regard du prix du produit. En effet, vu son prix élevé, la qualité et notamment la tendreté de la viande bovine sont souvent jugées décevantes et irrégulières. Ce point représente un défi majeur à relever par la filière bovine confrontée à la concurrence des viandes blanches offrant un rapport qualité/prix plus attractif pour les consommateurs.

Face à la complexité de ce problème, des stratégies différentes voire opposées ont été mises en œuvre par les scientifiques ou les professionnels en fonction des pays et des caractéristiques de la filière bovine concernée. Certains chercheurs ont essayé de développer des méthodes en SPIR qui s'avèrent satisfaisantes pour prédire le $\mathrm{pH}$ ou les critères de couleur, prometteuses pour prédire la perte en eau, mais pas pertinentes pour prédire la force de cisaillement (de Marchi 2013). En Europe, les autorités et les filières sont attachées au système des signes officiels de qualité (AOC/AOP, IGP, Label rouge...) dont le principe est l'établissement d'un cahier des charges au niveau de la production des viandes qui est supposé garantir l'origine et/ou la qualité du produit (appréciée par des tests hédoniques dans le cas du Label 
Rouge). En Australie, les professionnels et les chercheurs ont considéré que la méthode de référence d'appréciation de la tendreté devait être le test de dégustation par des consommateurs non entraînés (figure 3 ). La standardisation de ce type de méthode afin d'en améliorer la répétabilité et la fiabilité, ainsi que l'accumulation des répétitions (chaque échantillon est consommé par 10 consommateurs) au cours de nombreuses années (plus de 600000 échantillons testés depuis 1996) ont permis des analyses statistiques robustes sur des jeux de données très conséquents. Cette approche a permis de construire un système de prédiction de la qualité en bouche à destination des consommateurs connu sous l'appellation "Meat Standards Australia » (Watson et al 2008a et b, figure 3). Il est toutefois important de préciser, que ce soit pour les tests avec des consommateurs entrainés ou non, que les protocoles utilisés, notamment les modes (four, grill ou bouilli) et les températures de cuisson, diffèrent selon les pays : les échantillons étudiés peuvent être cuits avec une température à cœur de $55-60^{\circ} \mathrm{C}$ comme en France (Dransfield et al 2003, Allais et al 2010) ou à $70^{\circ} \mathrm{C}$ comme aux USA (Wheeler et al 1997) et au Royaume-Uni (Nute 2002), induisant ainsi des différences dans les résultats lorsque différents échantillons sont comparés (Micol et al 2010). Toutefois, malgré ces différences de méthodes de cuisson, le «Meat Standards Australia » permet de prédire correctement la qualité de la viande bovine en France (Legrand et al 2013). D'autres acteurs continuent de considérer que l'analyse des propriétés mécaniques de la viande (force de compression, force de cisaillement) sur viande crue ou cuite est plus pertinente en raison de sa plus grande répétabilité. Le test de Warner-Bratzler (force de cisaillement) est largement employé dans de nombreux pays avec de la viande maturée cuite pour déterminer une note de dureté mécanique qui se rapproche de la perception en bouche des consommateurs. Il est donc parfois considéré comme une méthode de référence.

Les fronts de science dans l'espèce bovine consistent à déterminer les meilleurs indicateurs de la qualité de la viande que ce soit des caractéristiques musculaires, des expressions de gènes ou de protéines ou des marqueurs génétiques (figure 3). Sur le plan méthodologique, cela implique des recherches en amont pour déterminer le pouvoir de prédiction de ces indicateurs et le développement de méthodes de mesure peu onéreuses et faciles à mettre en œuvre

Figure 3. Démarche de prédiction de la qualité de la viande bovine (adaptée de Watson et al 2008b).

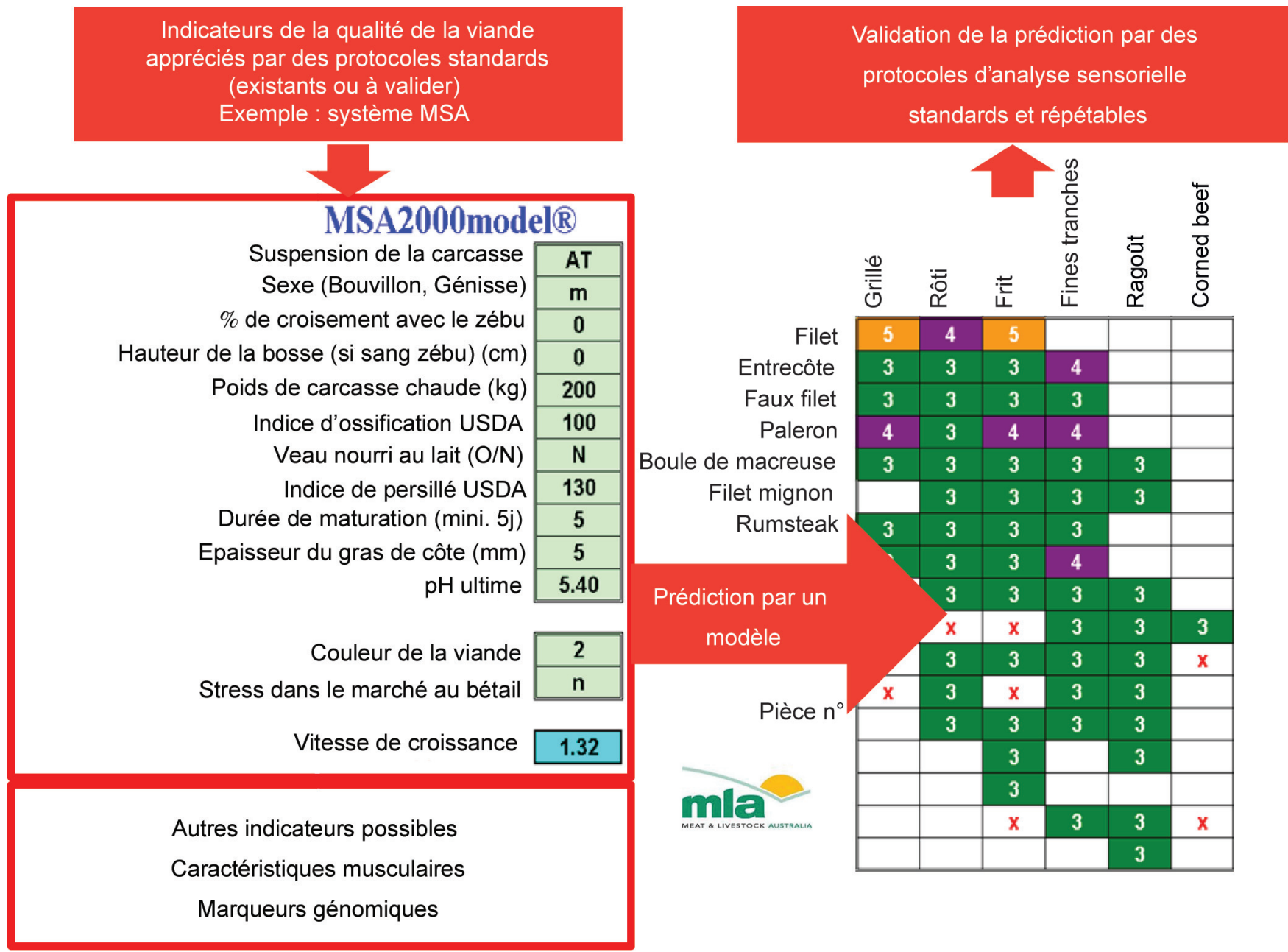

En Australie, la méthode de référence d'appréciation de la tendreté est le test de dégustation par des consommateurs non entraînés selon des protocoles standards utilisés depuis presque 20 ans. Cette méthode a permis d'accumuler un grand nombre de données comparables et de construire un système de prédiction de la qualité en bouche à destination des consommateurs connu sous l'appellation MSA pour «Meat Standards Australia ». Ce modèle est basé sur des équations de prédiction spécifiques à chaque pièce de viande. Les meilleurs indicateurs de la qualité de la viande bovine retenus en Australie par le système MSA sont indiqués sur la gauche. Ils peuvent potentiellement être enrichis par d'autres indicateurs tels que des caractéristiques musculaires, des expressions de gènes ou de protéines, ou des marqueurs génétiques. Les niveaux de qualité sont indiqués sur la droite ( 3 : bon pour une consommation courante, 4 : très bon, 5 : excellent). 
en routine. La dernière étape (et non la moindre) est la mise en œuvre de métaanalyses avec des grands jeux de données (Chriki et al 2012, 2013), puis la recherche d'équations de prédiction ou la construction de modèles pour prédire au mieux la tendreté de la viande avec l'ensemble de ces indicateurs. Jusqu'à présent, que ce soit dans le cas d'indicateurs biochimiques (Chriki et al 2013) ou génomiques (Hocquette et al 2009, 2012), les équations de prédiction de la qualité de la viande sont spécifiques d'un type d'animal (vaches, taurillons, bœufs), d'un type de muscle ou de conditions d'élevage, ces dernières modifiant les caractéristiques musculaires spécifiquement selon les muscles (CassarMalek et al 2004). Cela plaide pour des équations de prédiction de la qualité de la viande qui soient spécifiques de chaque type de muscle comme cela a été d'ailleurs réalisé dans le cadre du « Meat Standards Australia » (figure 3).

\section{c) Les poissons}

La chair de poisson est un produit carné et les questions de qualité précédemment décrites pour les viandes, qualités technologiques (poissons entiers, carcasses ou filets), qualités nutritionnelles et qualités sensorielles, sont également pertinentes. La diversité des espèces concernées, et donc des biologies associées, et l'organisation même de la musculature des poissons présentent néanmoins des particularités marquées qui ont des conséquences sur les phénotypes de qualité. La qualité technologique dépend fortement des espèces concernées. Ainsi, dans le cas des espèces élevées jusqu'à des stades " grande taille » comme les salmonidés (saumon, truite), vendus après transformation, la maîtrise des rendements de découpe est une question importante. En termes de recherches, cela se traduit par l'étude des déterminismes biologiques de ces rendements. Deux phénotypes clés en ressortent avec d'une part, des caractères permettant de décrire l'importance et la répartition des masses adipeuses et d'autre part, la description fine de la morphologie des animaux (répartition des masses musculaires). Comme les poissons peuvent stocker les lipides au niveau du foie, dans la cavité péri-viscérale ou au niveau musculaire, l'abondance de ces tissus adipeux va déterminer les rendements (carcasse, filets), mais aussi l'aptitude à la transformation (pour le fumage en particulier). Ce stockage préférentiel dépend de l'espèce et même des espèces proches, comme le saumon Atlantique et la truite arc-en-ciel, peuvent avoir des capacités de stockage différentes selon les sites, notamment musculaire vs périviscéral (Médale 2009). Pour une même espèce, un fort déterminisme génétique a pu être démontré avec la possibilité, chez la truite arc-en-ciel, d'orienter le stockage préférentiellement dans le muscle ou en péri-viscéral via la sélection génétique (Quillet et al 2007). En plus des conséquences économiques et pratiques, la maitrise du niveau d'adiposité musculaire va conditionner la qualité nutritionnelle et sensorielle des produits.

La chair de poisson présente les qualités nutritionnelles d'un produit carné (apport protéique, composition en acides aminés), avec en plus la présence de certains minéraux, vitamines et oligoéléments particulièrement intéressants (Médale et al 2003). Néanmoins, la principale qualité nutritionnelle de la chair de poisson est son apport en Acides Gras PolyInsaturés (AGPI) de la série n-3 (EPA et DHA). Cette qualité résulte directement de la nature de l'aliment puisque la composition en acides gras de la chair de poisson est le reflet de la composition en acides gras de l'aliment (Médale 2009). L'évolution actuelle de la nature des matières premières dans les aliments commerciaux, du fait de la raréfaction des farines et huiles de poissons issues de sous-produits de la pêche, peut remettre en cause cette qualité. La substitution des farines et huiles de poissons par les farines et huiles d'autres origines ne garantit pas une composition en acides gras assurant le maintien de la qualité nutritionnelle du produit. La compréhension et la maitrise de la capacité de dépôt et/ou de synthèse des AGPI chez les poissons est une question essentielle pour le maintien de la qualité nutritionnelle du produit. La quantification des différents acides gras nécessite des méthodes longues et couteuses (en chromatographie en phase gazeuse) et la mise au point de méthodes alternatives de phénotypage est un enjeu important pour ces recherches.

Parmi les qualités organoleptiques, la texture de la chair de poisson est déterminante pour les transformateurs comme pour les consommateurs. Pour le produit cru, l'intégrité et la texture des filets déterminent leur apparence et leur aptitude à la transformation, mais la texture (fermeté, jutosité, onctuosité) est également une qualité essentielle des produits cuits ou transformés par d'autres procédés tels que la fumaison. La texture de la chair des poissons dépend principalement de la nature, de la qualité et de l'organisation des composés protéiques musculaires (myofibrilles et matrice extra-cellulaire), mais aussi des lipides intra-musculaires. La compréhension du déterminisme de la texture reste une question essentielle et passe par une caractérisation fine et multiéchelle du muscle (composition, architecture) qui requiert de nombreuses méthodologies (rhéologie, biochimie, transcriptomique, histologie, analyse d'image). Des résultats récents montrent un déterminisme génétique de la texture des filets crus dont les bases biologiques restent à déterminer. L'évolution de la composition des aliments pour poissons, évoquée précédemment, ou des systèmes de production peuvent modifier notablement la qualité et il apparait nécessaire de conforter nos connaissances sur la relation entre les caractéristiques musculaires et la qualité de la chair.

\section{2 / Le lait}

La filière laitière est un point de convergence de nombreux secteurs d'activité de la sélection et de l'alimentation animale à la nutrition humaine. Le lait est le pivot entre l'amont et l'aval de la filière, mais paradoxalement sa caractérisation en matière de qualité intrinsèque est restée assez frustre, quasiment limitée à l'analyse des taux de cellules somatiques et de quelques contaminants (qualité sanitaire) et des quantités totales de matières grasses et protéiques en lien avec la qualité nutritionnelle et technologique. Le lait est considéré comme une matière première alimentaire noble apportant protéines, matières grasses, sucres, minéraux et micro-éléments. Cependant, la variabilité de ses éléments constitutifs, en particulier la variabilité du profil en acides gras ou protéines, n'est pas ou peu valorisée, ni au niveau de la production, ni au niveau de la transformation, bien que la composition fine du produit final consommé reflète largement la composition du lait d'origine (Lucas et al 2006). Aujourd'hui, il apparaît à la fois possible et souhaitable de progresser vite sur la caractérisation fine du lait afin d'en maîtriser la qualité en activant les leviers amonts et d'assurer une optimisation de son utilisation en aval de la filière (Peyraud et Duhem 2013).

La bibliographie est relativement abondante sur les liens entre différents facteurs de production (système d'élevage et alimentation en particulier, génétique) et composition du lait. C'est particulièrement vrai pour les acides gras (Ferlay et al 2013) ou les protéines majeures. La compréhension du fonctionnement de la glande mammaire et de ses facteurs de régulation a également connu ces dernières années des développements importants (Leroux et al 2013). Même si nous sommes encore loin de tout comprendre de la fonction de lactation, ces travaux sont sources de biomarqueurs, ou encore de nouvelles pistes de maîtrise de la qualité du lait via la nutrigénétique (Mutch et al 2005) et l'optimisation de la combinaison entre alimentation et génome de l'animal. Ces travaux reposent sur des outils et méthodes de phénotypage de plus en plus résolutifs à l'échelle moléculaire. On parle généralement de phénotypage « vertical » (Hocquette et al 2011). 
Toutefois ces travaux, sauf exceptions (du polymorphisme de la caséine alpha-s1 en caprin, ou encore de l'utilisation de la supplémentation en graine lin pour améliorer le profil en acides gras du lait en filière Bleu-Blanc-Cœur, Doreau et al 2011), sont encore peu valorisés dans les filières actuelles. Plusieurs initiatives récentes visent, par le développement de méthodes de phénotypage à haut débit de type horizontal (Hocquette et al 2011), à développer des références appliquées et adaptées aux filières. La création de l' "International Milk Genomic Consortium » (German 2004) témoigne de cette évolution intégrative de plusieurs disciplines pour améliorer la qualité des produits laitiers. Parmi ces initiatives, la première est la «Dutch Milk Initiative » (Visker et al 2006). On peut citer également le projet scandinave "Milkgenomics" ( $\underline{\text { www. }}$ milkgenomics.dk). En France, un projet de cette nature a été mis en œuvre à partir de 2008 : le projet PhénoFinlait (Esvan et al 2010). Ce projet, en s'appuyant sur des innovations en matière de méthode de phénotypage comme la spectrométrie dans le moyen infrarouge (MIR) (Soyeurt et al 2006, Ferrand-Calmels et al 2014) et la chromatographie en phase liquide couplée à la spectrométrie de masse (Miranda et al 2011), constitue un premier pas majeur vers une meilleure qualification et maîtrise de la composition fine du lait en acides gras et protéines, à grande échelle au sein des fílières. Il ne s'agit néanmoins que d'un premier pas, car il convient d'étendre cette approche à d'autres composants (minéraux y compris le calcium particulièrement important pour les produits laitiers mais dont les sources de variabilité sont pas ou mal connues, vitamines - Ferlay et al 2013 -, glucides, complexes immuns), à d'autres niveaux de raffinement (exploiter l'extrême diversité protéique) et à un niveau macromoléculaire (Léonil et al 2013) pour s'approcher au plus près des disponibilité et fonctionnalité réelles des différentes molécules. Sur le plan de la santé du consommateur, l'intérêt des différents peptides (Meisel et al 2005) est très lié à leur présentation sous forme de protéines (impact sur la biodisponibilité et le potentiel bioactif). La possibilité de qualifier analytiquement la diversité structurale des protéines laitières (Miranda et al 2011) offre de nouvelles voies pour leur valorisation. Les méthodes spectrales seront vraisemblablement insuffisamment résolutives dans ce cas.

Dans le même temps, il faut développer les liens entre ces caractéristiques intrinsèques de composition et les propriétés nutritionnelles, technologiques, fonctionnelles ou encore organoleptiques du lait ou produits dérivés. Bien qu'une partie de ces liaisons soient du ressort d'autres secteurs de recherche (nutrition humaine en particulier), un certain nombre de ces propriétés doivent être intégrées dans des protocoles de phénotypage (dans le cas des aptitudes à la transformation par exemple) afin de définir des modèles prédictifs applicables à partir de mesures directes dans le lait. Ces modèles peuvent mettre en relation quasiment directement certaines mesures, en particulier la spectrométrie MIR, et les phénotypes d'intérêts (O'Callaghan et al 2002, De Marchi et al 2007, Colinet et al 2013) ou lier la composition en certains éléments aux phénotypes d'intérêts (profil protéique et fromageabilité par exemple). L'enjeu de ces modèles et méthodes d'analyse est de permettre un phénotypage précoce, à moindre coût et à plus ou moins grande échelle de telle sorte que dès l'élevage tout puisse être mis en œuvre (sélection, gestion du troupeau, alimentation...) pour produire le lait le plus adapté à sa valorisation finale auprès des consommateurs et optimiser les procédés de transformation (orientation du lait en fonction de sa qualité, adaptation des procédés aux variations de potentialités des laits).

Enfin le lait, dont l'échantillonnage est aisé durant la lactation et dont la composition résulte à la fois des fermentations ruminales, des synthèses mammaires et de transferts directs depuis le sang (urée, protéines sériques...), apparait de plus en plus comme source de biomarqueurs ou de signatures à la fois du statut physiologique de l'animal et de son alimentation. Nous pouvons citer trois travaux d'importance dans ce domaine :

- la discrimination des laits à l'aide de l'infrarouge selon leurs conditions de production (race, fourrage dominant, altitude) (Valenti et al 2013). Ce travail ne se situe pas à l'échelle de l'animal, on ne peut donc pas parler de phénotypage, néanmoins il s'agit d'une caractérisation d'un

Figure 4. Démarche de prédiction des caractéristiques des bovins laitiers à partir du spectre du lait dans le moyen infrarouge.
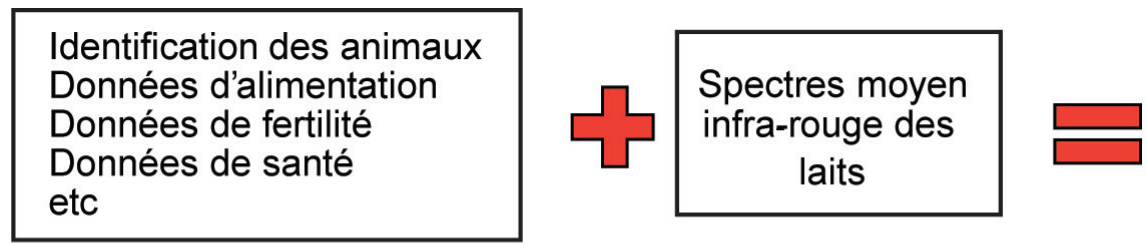

\section{Base de données}
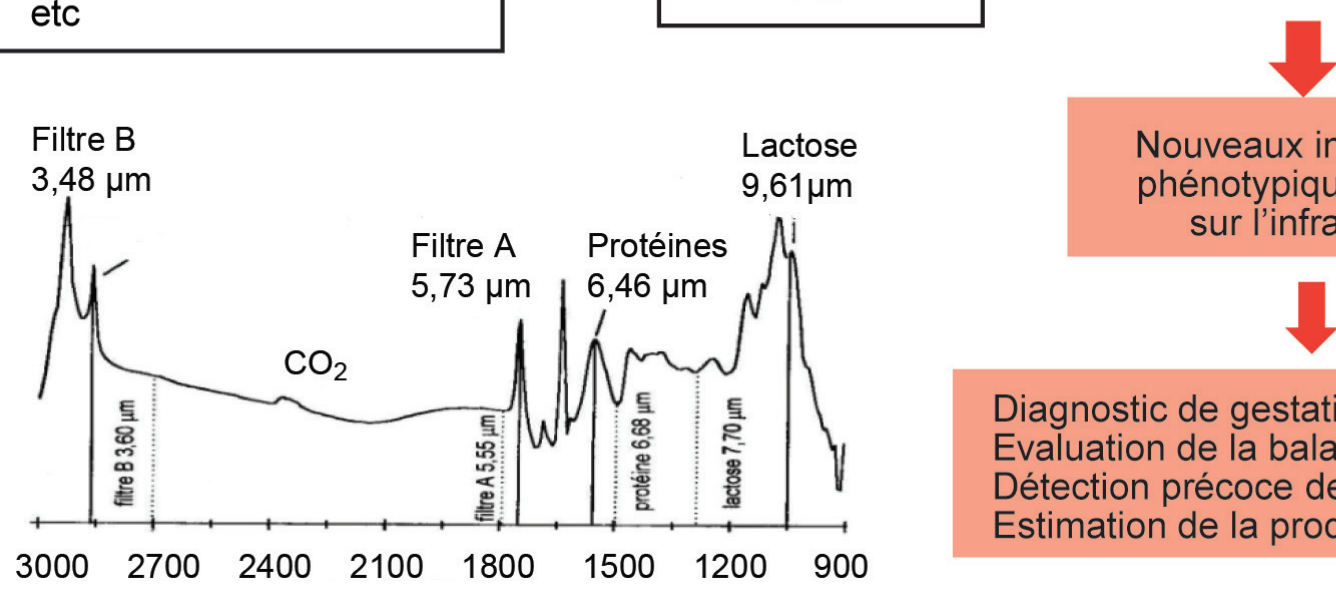

Diagnostic de gestation

Evaluation de la balance énergétique Détection précoce des mammites Estimation de la production de méthane

La spectrométrie dans le moyen infrarouge (MIR), qui est une technique à haut débit, rapide et répétable, constitue un premier pas majeur vers une meilleure qualification et maîtrise de la composition fine du lait en acides gras et protéines. Couplée à des données de performances ou de caractéristiques des animaux, cette démarche peut potentiellement aider à détecter de nouveaux indicateurs phénotypiques (diagnostic de gestation, évaluation de la balance énergétique, détection précoce des mammites, estimation de la production de méthane) (Dehareng 2011). 
des aspects de la qualité des produits (origine, systèmes de production) ;

- la détection et la valorisation de variations du spectre MIR pour caractériser le statut physiologique (gestation par exemple) et sanitaire (maladies métaboliques, infections mammaires) des femelles dans le cadre du projet européen OptiMir (Dehareng 2011, figure 4), et dans les projets labellisés CASDAR AcID et $M A M O V I C A P$;

- le développement, pour certaines rations, de modèles prédictifs des rejets de méthane entérique s'appuyant sur le profil en AG du lait (14 modèles prédictifs répertoriés par Beillevert 2012).

Le lait est donc une source d'information encore largement sous-exploitée, mais qui prend une importance à différents niveaux, depuis l'élevage jusqu'au produit fini, et pour une très large palette de problématiques (santé, réduction de l'empreinte environnementale, compétitivité des filières). Les méthodes de phénotypage de la qualité du lait et de sa composition en général par le MIR sont, comme nous venons de le voir, à l'origine de nombreux développements et offrent des perspectives importantes de transfert à grande échelle (figure 4). Néanmoins, le calibrage et l'entretien de ces méthodes spectrales nécessitent la constitution, grâce à des méthodes de référence et des échantillonnages adaptés, de bases de données variables et adaptées aux populations cibles (populations concernées par l'emploi des équations MIR).

\section{3 / Les œufs}

La sélection des pondeuses commerciales utilise une combinaison de critères (Beaumont et al 2010). La priorité a été donnée au nombre d'œufs produits et à la réduction de la quantité d'aliment pour faire un œuf, ce qui a conduit à une réduction importante du poids des poules. De plus, une sélection orientée vers un nombre maximal d'œufs, à poids d'œuf supposé constant, induit à long terme une diminution de la part de jaune (de - 1 à - 1,5 point). La part des constituants (et en particulier le ratio entre le poids du jaune et le poids de l'œuf) doit donc être prise en compte dans tout programme de sélection. La qualité sanitaire de l'œuf reste néanmoins le premier critère de qualité car, consommé cru, l'œuf est à l'origine de toxi-infection alimentaire chez l'Homme $(60 \%$ des cas de Salmonellose). La sélection sur la solidité de la coquille a toujours été un critère important pour éviter la pénétration bactérienne. Elle est appréciée par des mesures directes de déformation ou de rupture ou par des mesures indirectes destructives (poids de la coquille rapporté à $100 \mathrm{~g}$ d'œuf) ou non (densité de l'œuf). Des systèmes acoustiques (sonde à ultrasons) ont aussi été développés pour mesurer précisément l'épaisseur de coquille en tout point de l'œuf et détecter la présence de micro-fêlures (Beaumont et al 2010). La qualité interne (blanc principalement) a été incluse depuis une quinzaine d'année dans l'index avec une sélection notamment sur les unités Haugh considérées comme un critère de fraîcheur de l'œuf ou sur la réduction de défauts tels que les taches de sang à l'aide de mesures optiques au travers de la coquille.

Si ces critères phénotypiques classiques restent toujours d'actualité, les efforts de recherche récents ont mis en évidence de nouveaux biomarqueurs des systèmes de protection de l'œuf. Il s'agit des protéines de la coquille qui contrôlent sa minéralisation et lui permettent d'agir en tant que barrière physique, et des protéines jouant un rôle antimicrobien, présentes dans tous les constituants de l'œuf et assurant sa défense chimique. Dans le cadre des programmes européens EggDefence et $S A B R E$, les protéines et les gènes potentiellement impliqués dans les propriétés mécaniques de la coquille ont été caractérisés par des approches à haut débit (Gautron et al 2011). Les polymorphismes de gènes codant des protéines impliquées dans la calcification de la coquille ont été établis et testés sur des dispositifs génétiques. Les résultats ont montré une association entre le polymorphisme de certains de ces gènes et des caractères phénotypiques de solidité de la coquille (Dunn et al 2009). Au cours du programme $S A B R E$, les transcrits différentiellement exprimés dans l'utérus pendant la calcification de la coquille ont été localisés sur les chromosomes de la poule (Jonchère et al 2010) et associés à des QTL expliquant environ $5 \%$ de la variabilité phénotypique de la solidité de la coquille. Des approches fines et complémentaires seront nécessaires pour déterminer les gènes et groupes de gènes contrôlant une part significative de la variabilité de ces caractères.

Les avancées récentes obtenues grâce à l'essor de la génomique fonctionnelle ont démontré que l'œuf de poule est une source importante de molécules dotées d'activités biologiques très diverses et notamment antimicrobiennes (RéhaultGodbert et al 2011). Des tentatives ont été réalisées dans le cadre du programme Rescape pour renforcer des activités antimicrobiennes de l'œuf, mais l'association observée entre des polymorphismes au sein de gènes codant pour des protéines antibactériennes et l'activité antisalmonellique du blanc d'œuf était d'amplitude trop faible pour être exploitée en génétique. Les études à plus large échelle de l'impact de la génétique, du système d'élevage ou du mode de conservation des œufs sur les protéines et peptides anti microbiens vont demander un effort important de développement de méthodes de quantification à haut débit de ces molécules, applicables aux différents compartiments de l'œuf. Il en va de même pour le développement de micro-méthodes de mesure de l'activité antibactérienne du blanc d'œuf.

\section{Conclusion}

Au côté des aspects quantitatifs de la production, la qualité du produit a depuis longtemps été prise en compte par les filières de productions animales, en termes de sélection ou de choix de modes d'élevage permettant une démarcation qualitative des produits. Aujourd'hui, les exigences de qualité se diversifient en réponse aux évolutions des modes de consommation et aux demandes des consommateurs-citoyens. Les travaux des équipes de recherche appuyées par les filières visent une caractérisation plus fine de la qualité du produit et le développement de mesures prédictives ou de biomarqueurs. Les développements importants des méthodes spectrales montrent qu'il est possible de trouver des technologies plus rapides, faciles d'utilisation et non destructives de prédiction de la qualité avec de larges applications pour les productions animales à l'instar des productions végétales. Les outils d'analyse à haut débit rendent aussi possible l'identification de marqueurs biologiques ou génétiques de la qualité accessibles sur l'animal, avec des champs d'application très larges en sélection et en élevage. L'accès à ce large phénotypage de la qualité demeure un enjeu majeur pour permettre de nouvelles voies de valorisation des produits animaux et promouvoir les systèmes d'élevage dans leur diversité.

\section{Remerciements}

Les auteurs remercient vivement Koenraad Duhem (Institut de l'élevage) et Didier Boichard (INRA, UMR GABI) pour leur contribution à l'élaboration de l'article pour la partie « lait» ainsi que Jérôme Bugeon (INRA, LPGP) pour la partie « poisson ». 


\section{Références}

Allais S., Levéziel H., Payet-Duprat N., Hocquette J.F., Lepetit J., Rousset S., Denoyelle C., Bernard-Capel C., Journaux L., Bonnot A., Renand G., 2010. The two mutations, Q204X and nt821, of the myostatin gene affect carcass and meat quality in young heterozygous bulls of French beef breeds. J. Anim. Sci., 88, 446-454.

Bastianelli D., Bonnal L., Chartrin P., Bernadet M.D., Marie-Etancelin C., Baéza E., 2009. Near-infrared reflectance spectroscopy for predicting lipid content in duck breast meat. In: XIX WPSA Eur. Symp. Qual. Poult. Meat, Turku, Finland, 1-9.

Beaumont C., Calenge F., Chapuis H., Fablet J., Minvielle F., Tixier-Boichard M., 2010. Génétique de la qualité de l'œuf. In : Numéro spécial, Qualité de l'œuf. Nys Y. (Ed). INRA Prod. Anim., 23, 123-132.

Beillevert M., 2012. Evaluation des équations de prédiction du méthane entérique émis par les vaches laitières à partir des caractéristiques de la ration et du profil en acides gras du lait. Rapport de stage. Institut de l'Elevage, INRA, ESA.

Berge P., Ratel J., Fournier A., Jondreville C., Feidt C., Roudaut B., Le Bizec B., Engel E., 2011. Use of Volatile Compound Metabolic Signatures in Poultry Liver to Back-Trace Dietary Exposure to Rapidly Metabolized Xenobiotics. Environ. Sci. Technol., 45, 65846591.

Berri C., Le Bihan-Duval E., Gigaud V., Baéza E., Duclos M.J., 2010. Towards the identification of mechanisms underlying the variations of chicken meat processing ability. In: $13^{\text {th }}$ Eur. Poult. Conf. (WPSA France), Tours, France, 9 p.

Bothwell J.H.F., Griffin J.L., 2011. An introduction to biological nuclear magnetic resonance spectroscopy. Biol. Rev., 86, 493-510.

Cassar-Malek I., Hocquette J.F., Jurie C., Listrat A., Jailler R., Bauchart D., Briand Y., Picard B., 2004. Muscle-specific metabolic, histochemical and biochemical responses to a nutritionally induced discontinuous growth path. Anim. Sci., 204, 79-59.

Chabault M., Baéza E., Gigaud V., Chartrin P., Chapuis H., Boulay M., Arnould C., D'Abbadie F., Berri C., Le Bihan-Duval E., 2012. Analysis of a slow-growing line reveals wide genetic variability of carcass and meat quality-related traits. BMC Genetics, 13, 90.

Chartrin P., Rousseau X., Gigaud V., Bastianelli D., Baéza E., 2010. Near-infrared reflectance spectroscopy for predicting lipid content in chicken breast meat. In: Eur. Poult. Conf., (WPSA France), Tours, France, 4 p.

Chriki S., Gardner G.E., Jurie C., Picard B., Micol D., Brun J.P., Journaux L., Hocquette J.F., 2012. Cluster analysis application in search of muscle biochemical determinants for beef tenderness. BMC Biochem., 13, 29.

Chriki S., Renand G., Picard B., Micol D., Journaux L., Hocquette J.F., 2013. Meta-analysis of the relationships between beef tenderness and muscle characteristics. Livest. Sci., 155, 424-434

Colinet F.G., Troch T., Abbas O., Baeten V., Dehareng F., Froidmont E., Soyeurt H., Dardenne P., Sindic M., Gengler N., 2013. Potentiel d'utilisation de la spectrométrie moyen infrarouge pour prédire le rendement fromager du lait et étudier sa variabilité génétique. Renc. Rech. Rum., 153-156.

Culioli J., 1998. La qualité de la viande bovine Aspects biologiques et technologiques de la gestion de la tendreté. Bull. Acad. Vét. de France, 71, 25-46.

Davenel A., Bazin C., Quellec S., Challois S., Gispert M., Mercat M.J., Muller N., 2012 . Dosage haut débit des lipides intramusculaires de la viande de porc par imagerie par résonance magnétique. Journ. Rech. Porcine., 44, 53-54.

Dehareng F., 2011. OptiMIR: new tools for a more sustainable dairy sector. ICAR, June 2011, Bourg-en-Bresse, France.

De Marchi M., Dal Zotto R., Cassandro M., Bittante G., 2007. Milk coagulation ability of five dairy cattle breeds. J. Dairy Sci., 90, 39863992.

De Marchi M., 2013. On-line prediction of beef quality traits using near infrared spectroscopy. Meat Sci., 94, 455-460.

Dockès A.C., Magdelaine P., Daridan D., Guillaumin A., Rémondet M., Selmi A., Gilbert H., Mignon-Grasteau S., Phocas F., 2011. Attentes en matière d'élevage des acteurs de la sélection animale, des filières de l'agroalimentaire et des associations. In : Numéro spécial, Amélioration génétique. Mulsant P., Bodin L., Coudurier B., Deretz S., Le Roy P., Quillet E., Perez J.M. (Eds). INRA Prod. Anim., 24, 285-296.

Doreau M., Bauchart D., Chilliard Y., 2011 Enhancing fatty acid composition of milk and meat through animal feeding. Anim. Prod. Sci., $51,19-29$.

Dransfield E., Zamora F., 1997. Beef steak: What price tenderness? Viandes et Produits Carnés, 18, 185-188.

Dransfield E., Martin J.F., Bauchart D., Abouelkaram S., Lepetit J., Culioli J., Jurie C., Picard B., 2003. Meat quality and composition of three muscles from French cull cows and young bulls. Anim. Sci., 76, 387-399.

Dunn I.C., Joseph N.T., Bain M., Edmond A., Wilson P.W., Milona P., Nys Y., Gautron J., Schmutz M., Preisinger R., Waddington D., 2009. Polymorphisms in eggshell organic matrix genes are associated with eggshell quality measurements in pedigree Rhode Island Red hens. Anim. Genet., 40, 110-114.

EFSA, 2011. The European Union summary report on trends and sources of zoonose, zoonotic agents and food-borne outbreaks in 2009. EFSA J. 9, 2090-2468.

Esvan S., Dragan C., Varenne A., Astruc J.M., Barillet F., Boichard D., Brunschwig P., Dubrulle A., Faucon-Lahalle F., Ferlay A., Lagrifoul G., Larroque H., Legarto J., Palhière I., Peyraud J.L., Rupp R., Brochard M., 2010. PhénoFinlait, 1 ers résultats : influence de l'alimentation, de l'état physiologique et de la génétique sur la composition en acides gras des laits de vache, brebis et chèvre. Renc. Rech. Rum., 17, 385-388.

Ferlay A., Graulet B., Chilliard Y., 2013. Maîtrise par l'alimentation des teneurs en acides gras et en composés vitaminiques du lait de vache. In : Numéro spécial, La vache et le lait. Faverdin P., Leroux C., Baumont R. (Eds). INRA Prod. Anim., 26, 177-192.

Ferrand-Calmels M., Palhière I., Brochard M., Leray O., Astruc J.M., Aurel M.R., Barbey S.,
Bouvier F., Brunschwig P., Caillat H., Douguet M., Faucon-Lahalle F., Gelé M., Thomas G., Trommenschlager J. M., Larroque H., 2014. Prediction of fatty acid profiles in cow, ewe, and goat milk by mid-infrared spectrometry. J. Dairy Sci., 97, 1-19.

Feurer C., Christieans S., Rivollier M., Leroy S., Talon R., Champomier-Vergès M., Zagorec M., Desmonds M.H., 2013. Les applications de la biopréservation via des cultures microbiennes dans la filière des produits laitiers et fromagers. In : Flores protectrices pour la conservation des aliments, Zagorec M., Christieans S. (Eds). Quae Editions, Versailles, France, 69-85.

Fujii J., Otsu K., Zorzato F., de Leon S., Khanna V.K., Weiler J.E., O’Brien P.J., MacLennan D.H., 1991. Identification of a mutation in porcine ryanodine receptor associated with malignant hyperthermia. Science, 253, 448-451.

Gautron J., Rehault-Godbert S., Nys Y., Mann K., Righetti P.G., 2011. Use of high-throughput technology to identify new egg components. In: Improving the safety and quality of eggs and egg products. Vol.1 Egg chemistry, production and consumption. Nys Y., Bain M., Van Immerseel F., (Eds). Woodhead Publishing in Food Science, Technol. Nutr., 213, Cambridge, GBR, Woodhead Publishing Ltd., 133-150.

Geay Y., Bauchart D., Hocquette J.F., Culioli J., 2001. Effect of nutritional factors on biochemical, structural and metabolic characteristics of muscles in ruminants, consequences on dietetic value and sensorial qualities of meat. Reprod. Nutr. Dev., 41, 1-26, erratum 41, 337.

\section{German B., 2004. http://milkgenomics.org}

Grisart B., Coppieters W., Farnir F., Karim L., 2002. Positional candidate cloning of a QTL in dairy Cattle: identification of a missense mutation in the bovine DGAT1 Gene with major effect on milk yield and composition. Genome Res., 12, 222-231.

Grunert K. G., Bredahl L., Brunso K., 2004. Consumer perception of meat quality and implications for product development in the meat sector - a review. Meat Sci., 66, 259-272.

Hanne H., Roux N., 2012. Evolution des dépenses et des prix d'alimentation dans la consommation des ménages en France et en Europe depuis 1959. Dgcerf éco, (http://www.economie.gouv.fr/files/directions services/dgccrf/do cumentation/dgccrf eco/dgccrf_eco4.pdf). [cited 29 June 2013].

Hocquette J.F., Renand G., Dufour E., Lepetit J., Nute G.R., 2007. Traditional and new methods to assess meat quality. In: Evaluation of carcass and meat quality in cattle and sheep. Lazzaroni C., Gigli S., Gabiña D. (Eds), EAAP Publication 123, Wageningen Academic Publishers, Wageningen, The Netherlands, 61-80.

Hocquette J.F., Cassar-Malek I., Bernard C., Picard B., 2009. Functional genomics and new markers for beef production. Animal Science Papers and Reports, 27, 273-280.

Hocquette J.F., Capel C., David V., Guéméné D., Bidanel J., Barbezant M., Gastinel P.L., Le Bail P.Y., Monget P., Mormède P., Peyraud J.L., Ponsart C., Guillou F., 2011. Les objectifs et les applications d'un réseau organisé de phénotypage pour les animaux d'élevage. Renc. Rech. Rum, 18, 327-334.

Hocquette J.F., Bernard-Capel C., Vidal V., Jesson B., Levéziel H., Cassar-Malek I., 2012. 
The GENOTEND chip: a new tool to analyse gene expression in muscles of beef cattle for beef quality prediction. BMC Vet. Res., 8, 135.

Honkatukia M., Reese K., Preisinger R., Tuiskula-Haavisto M., Weigend S., Roito J., Mäki-Tanila A., Vilkki J., 2005. Fishy taint in chicken eggs is associated with a substitution within a conserved motif of the FMO3 gene. Genomics, 86, 225-232.

ISO 15884 / IDF 182 "Milk fat - preparation of fatty acid methyl esters", first edition 2002.7.

ISO 15885 / IDF 184 "Milk fat - determination of the fatty acid composition by gas- liquid chromatography", first edition 2002.

Jamet E., Irlinger F., Delbès-Paus C., Montel M.C., Fraud S., 2013. Les applications de la biopréservation via des cultures microbiennes dans la filière des produits laitiers et fromagers. In : Flores protectrices pour la conservation des aliments, Zagorec M., Christieans S. (Eds), Quae Editions, Versailles, France, 45-62.

Jez C., Beaumont C., Magdelaine P., 2010. La filière avicole française à l'horizon 2025. Une prospective INRA-ITAVI. INRA Prod. Anim., 23, 379-390.

Jonchère V., Rehault-Godbert S., HennequetAntier C., Cabau C., Sibut V., Cogburn L.A., Nys Y., Gautron J., 2010. Gene expression profiling to identify eggshell proteins involved in physical defense of the chicken egg. BMC Genomics, 11, 57, 19 p. DOI : 10.1186/14712164-11-57.

Lagarrigue S., Tixier-Boichard M., 2011. Nouvelles approches de phénotypage pour la sélection animale. In : Numéro spécial, Amélioration génétique. Mulsant P., Bodin L., Coudurier B., Deretz S., Le Roy P., Quillet E., Perez J.M. (Eds). INRA Prod. Anim., 24, 377 386.

Le Bihan-Duval E., Debut M., Berri C., Sellier N., Santé-L'Houtellier V., Jégo Y., Beaumont C., 2008. Chicken meat quality: genetic variability and relationship with growth and muscle characteristics. BMC Genetics, 9, 53.

Le Bihan-Duval E., Nadaf J., Berri C., Pitel F., Graulet B., Godet E., Leroux S., Demeure O., Lagarrigue S., Duby C., Cogburn L. A., Beaumont C., Duclos M., 2011. Detection of a Cis eQTL controlling BMCO1 gene expression leads to the identification of a QTG for chicken breast meat color. Plos One, 6, online (7), Non paginé. DOI : 10.1371/journal.pone. 0014825 .

Le Bihan-Duval E., Talon R., Hocquette J.F., 2013a. Les enjeux du phénotypage des animaux d'élevage pour la qualité des produits carnés. Viandes et Produits Carnés, -29-6-3 http://www.viandesetproduitscarnes.fr/phocadownload/vpc_vol_29/2963 duval phenotypage.pdf

Le Bihan-Duval E., Chabault M., Boulay M., Guardia S., Jégo Y., Baéza E., Berri C., 2013b. Sélection divergente sur le pH ultime du filet de poulet : premier bilan après quatre générations. In : Journ. Rech. Avicole et Palmipèdes à Foie Gras, La Rochelle, France, 513-517.

Legrand I., Hocquette J.F., Polkinghorne R.J., Pethick D.W., 2013. Prediction of beef eating quality in France using the Meat Standards Australia system. Animal, 7, 524-529.

Léonil J., Michalski M.C., Martin P., 2013. Les structures supramoléculaires du lait : structure et impact nutritionnel de la micelle de caséine et du globule gras. In : Numéro spécial, La vache et le lait. Faverdin P., Leroux C., Baumont R. (Eds). INRA Prod. Anim., 26, 2, 129-144.
Leroux C., Bernard L., Dessauge F., Le Provost F., Martin P., 2013. La fonction de lactation : régulation de la biosynthèse des constituants du lait. In : Numéro spécial, La vache et le lait. Faverdin P., Leroux C., Baumont R. (Eds). INRA Prod. Anim., 26, 2, 117-128.

Lucas A., Rock E., Chamba J.F., Verdier-Metz I., Brachet P. Coulon J.B., 2006. Respective effects of milk composition and the cheesemaking process on cheese compositional variability in components of nutritional interest. Lait, 86, 21-41.

Mairesse G., Douzenel P., Mourot J., Vautier A., Le Page R., Goujon J.M., Poffo L., Sire O., Chesneau G., 2012. La spectroscopie proche infrarouge : outil d'analyse rapide sur carcasse de la teneur en acides gras polyinsaturés n-3 des gras de bardière du porc charcutier. Journ. Rech. Porcine., 211-212.

Médale F., Lefèvre F., Corraze G., 2003. Qualité nutritionnelle et diététique des poissons, constituants de la chair et facteurs de variation. Cah. Nutr. Diet., 38, 37-44.

Médale F., 2009. Teneur en lipides et composition en acides gras de la chair de poissons issus de la pêche et de l'élevage. Cah. Nutr. Diet., 44, 173-181.

Meisel H., 2005. Biochemical properties of peptides encrypted in bovine milk proteins. Curr. Med. Chem., 12, 1905-1919.

Micol D., Jailler R., Jurie C., Meteau K., Juin H., Nute G., Richardson R. I., Hocquette J.F. 2010. Sensory evaluation of beef eating quality in France and UK at two cooking temperatures. In: Book of Abstracts of the 61 $1^{\text {st }}$ Ann. Meet. Eur. Assoc. Anim. Prod. (EAAP), 16. Wageningen Academic Publisher. Heraklion, Greece, 337.

Milan D., Jeon J.T., Looft C., Amarger V., Robic A., Thelander M., Rogel-Gaillard C., Paul S., Ianucelli N., Rask L., Ronne H., Lundström K., Reinsch N., Gellin J., Kalm E., Le Roy P., Chardon P., Andersson L., 2000. A mutation in PRKAG3 associated with excess glycogen content in pig skeletal muscle. Science, 288, 1248-1251.

Miranda G., Boumahrou N., Bianchi L., Pinard A., Saadaoui B., Guillot A., Henry C., Bevilacqua C., Beauvallet C., Bellier S., Cebo C., Martin P., 2011. Understanding milk protein complexity to produce accurate phenotypes. In: $8^{\text {th }}$ Int Milk Genom. Consortium Symp., Melbourne, Australia.

Morgan J. B., Savell J. W., Hale D. S., Miller R. K., Griffin D. B., Cross H. R., Shackelford S. D., 1991. National beef tenderness survey. J. Anim. Sci., 69, 3274-3283.

Mutch D.M., Wahli W., Williamson G., 2005. Nutrigenomics and nutrigenetics: the emerging faces nutrition. FASEB J., 19, 1602-1616.

Normand J., Rubat E., Evrat-Georgel C., Turin F., Denoyelle C., 2009. Enquête "nationale" sur la tendreté de la viande bovine proposée au consommateur français. Renc. Rech. Rum., 16, 147-150.

Nute G.R., 2002. Sensory analysis of meat. In: Sensory analysis of meat, Kerry J., John Kerry, Ledward David, (Eds), Woodhead Publishing Series in Food Science, Technology and Nutrition No. 76, Woodhead Publishing Ltd, Cambridge, UK, 175-192.

O'Callaghan D.J., O'Donnell C.P., Payne F.A. 2002. Review of systems for monitoring curd setting during cheesemaking. Int. J. Dairy Technol., 55, 65-74.
Owens C.M., Kuttappan V.A., 2013. Emerging poultry meat defect: White striping. In: Eur. Symp. Quality Poult. Meat, 15-19 September, Bergamo, Italy.

Petracci M., Baéza E., 2011. Harmonization of methologies for the assessment of poultry meat quality features. World Poult. Sci. J., 67, $137-$ 151.

Peyraud J.L., Duhem K., 2013. Les élevages laitiers et le lait demain: exercice d'analyse prospective. In : Numéro spécial, La vache et le lait. Faverdin P., Leroux C., Baumont R. (Eds). INRA Prod. Anim., 26, 2, 221-230.

Picard B., Berri C., Lebret B., Lefèvre F., Damon M., Liaubet L., Cassar-Malek I., Hocquette J.F., Renand G., 2012. Génomique et viande : Quelles avancées, quelles applications? In : $14^{\text {emes }}$ Journ. Sci. Muscle Technol. de la viande, Caen, France.

Quillet E., Bugeon J., Le Guillou S., Davenel A., Collewet G., Labbé L., Médale F., 2007. Effect of selection for muscle lipid content on body shape, fat deposition and dressing yields in rainbow trout. Aquaculture, 272, S303S303.

Rehault-Godbert S., Herve-Grepinet V., Gautron J., Cabau C., Nys Y., Hincke M., 2011. Molecules involved in chemical defence of the chicken egg. In: Improving the safety and quality of eggs and egg products. Egg chemistry, production and consumption. Nys Y., Bain M., Van Immerseel F. (Ed). Woodhead Publishing in Food Science, Technol. Nutr. Cambridge, GBR, Woodhead Publishing Ltd, 183-208.

Renand G., Larzul C., Le Bihan-Duval E., Le Roy P., 2003. L'amélioration génétique de la qualité de la viande dans les différentes espèces : situation actuelle et perspectives à court et moyen terme. INRA Prod. Anim., 16, 159-173.

Rohart F., Paris A., Laurent B., Canlet C., Molina J., Mercat M.J., Tribout T., Muller N., Ianucelli N., Villa-Vialaneix N., Liaubet L., Milan D., San Cristobal M., 2012. Phenotypic prediction based on metabolomic data for growing pigs from three main European breeds. J. Anim. Sci., 90, 4729-4740.

Soyeurt H., Dardenne P., Dehareng F., Lognay G., Veselko D., Marlier M., Bertozzi C., Mayeres P., Gengler N., 2006. Estimating fatty acid content in cow milk using Mid-Infrared Spectrometry. J. Dairy Sci., 89, 3690-3695.

Valenti B., Martin B., Andueza D., Leroux C., Labonne C., Lahalle F., Larroque H., Brunschwig P., Lecomte C., Brochard M., Ferlay A., 2013. Infrared spectroscopic methods for the discrimination of cow milk according to the feeding systems, cow breed and altitude of the dairy farms. Int. Dairy J., 32, 26-32.

Vautier A., Bozec A., Gault E., Lhommeau T., Martin J.L., Vendeuvre J.L., 2011. Visible spectroscopy and redox potential as alternatives of ultimate $\mathrm{pH}$ for cooking yield prediction. In: $57^{\text {th }}$ Int. Congr. Meat Sci. Technol., Ghent, Belgium, 7-12.

Velge P., Virlogeux-Payant I., Lalmanach A.C., Belloc C., Fravalo P., Vignal A., Beaumont C., 2008. Réduction du portage des salmonelles chez les animaux de rente : une approche multidisciplinaire. In : Numéro spécial, 20 ans de recherches en productions animales à l'INRA. B. Charley B., Herpin P., Perez J.M. (Eds) INRA Prod. Anim., 21, 117-126.

Verbeke W., Van Wezemael L., de Barcellos M.D., Kugler J.O., Hocquette J.F., Ueland O. 
Grunert K.G., 2010. European beef consumers' interest in a beef eating-quality guarantee insights from a qualitative study in four eu countries. Appetite, 54, 289-296.

Visker M., Heck J., Koks P., Leon-Kloosterziel K., Meuldijk R., Schennink A., Schopen G., Stoop M., van Arendonk J., 2006. The Dutch Milk Initiative: genetic improvement of milk quality traits and product innovation. $3^{\text {rd }}$ Int. Symp. Milk Genom. Human Health, Brussels, Belgium.
Watson R., Gee A., Polkinghorne R., Porter M. 2008a. Consumer assessment of eating quality -development of protocols for Meat Standards Australia (MSA) testing. Aust. J. Exp. Agr., 48, 1360-1367. DOI :10.1071/EA07176.

Watson R., Polkinghorne R., Thompson J.M., 2008b. Development of the Meat Standards Australia (MSA) prediction model for beef palatability. Aust. J. Exp. Agr., 48, 1368.1379. DOI :10.1071/EA07184
Wheeler T.L., Shackelford S.D., Johnson I.P. Miller M.F., Miller R.K., Koohmaraie M., 1997. A comparison of warner-bratzler shear force assessment within and among institutions. J. Anim. Sci., 75, 2423-2432.

\title{
Résumé
}

Maîtriser la qualité des produits issus des animaux d'élevage suppose de pouvoir l'objectiver à partir de mesures fiables, faciles d'utilisation et si possible précoces et non invasives. Les programmes de recherche-développement mis en place au sein des différentes filières animales (ruminants, porcins, volailles, poissons) concernent notamment $i$ ) la détection et la quantification des contaminants biologiques ou chimiques des produits, ii) la détermination de la composition et des propriétés technologiques des produits grâce à des méthodes alternatives aux mesures analytiques de laboratoire (mesures optiques ou par imagerie, mesures physiques non invasives), et iii) la recherche de marqueurs biologiques précoces de la qualité (marqueurs génétiques, expression de gènes ou de protéines, teneurs en métabolites) et leur validation par des approches de modélisation. Appliqué à un panel de plus en plus large de critères de qualité, ce phénotypage à haut débit est nécessaire au développement de la sélection génétique ou génomique, à la biologie prédictive et à l'élevage de précision.

\begin{abstract}
Phenotyping of animal product quality: challenges and innovations

In order to be able to control the quality of animal products, it is necessary to have reliable, easy to use and if possible early and non-invasive measurements. Research and development programs implemented in the various livestock sectors (ruminants, pigs, poultry, fish) concern $i$ ) the development and standardization of rapid methods both for the detection and quantification of biological or chemical contaminants, ii) the development of alternative methods to replace analytical measurements of the composition and functional properties of products through innovative technologies used in routine (optical or imaging methods, non-invasive physical methods...) and/or iii) the research of early biological markers of quality (genetic markers, gene expression or protein levels of metabolites) and their validation by the way of modeling. High-throughput phenotyping applied to a range of increasingly broad criteria of quality, is necessary for genetic or genomic selection, predictive biology and precision livestock.
\end{abstract}

LE BIHAN-DUVAL E., TALON R., BROCHARD M., GAUTRON J., LEFĖVRE F., LARZUL C., BAÉZA E., HOCQUETTE J.-F., 2014. Le phénotypage de la qualité des produits animaux : enjeux et innovations. In : Phénotypage des animaux d'élevage. Phocas F. (Ed). Dossier, INRA Prod. Anim., 27, 223-234. 